\title{
Study on Behavior Problems and Influencing Factors of School-age Children
}

\author{
Hongpin Zhang
}

School of Sports and Health, Linyi University, Linyi, Shandong Province, China

Keywords: school-age children; behavior problems; migrant workers; psychology.

\begin{abstract}
Through investigating parents and teachers of children from Linyi Primary School by Rutter Children Behavior Questionnaire, following phenomena are found: behavior problems of boys are more than those of girls; behavior problems of children from migrant worker families are more serious; children with poor academic performances are more likely to have behavior problems; children come from poor families and children who have parents with low cultural degrees have more behavior problems. Then suggestions are provided accordingly. First, society, school and family should pay more attention to the lives and mental health of children from migrant worker families. Second, academic achievement should not become the only criterion to judge children, in order to avoid children's psychological problems brought by poor academic performances. Third, the educational level of parents affects their educational methods, which will also affect children's growth. Therefore, parents should constantly improve their educational levels and learn some childcare knowledge.
\end{abstract}

\section{Introduction}

Behavior problems of children have serious consequences. They affect children's growth and socialization, and may cause anti-social behaviors and mental obstacle in their adulthood. In urban areas of our country, children's behavior problems show an obvious trend of growth. In 1993, the detection rate of behavior problems of children aged 4-6 years old in China was $(12.97+2.19) \%$ [1]; in 2005, the detection rate of behavior problems of school-age children in Beijing was $16.4 \%$ [2]; in 2006, the detection rate of behavior problems of school-age children in Shenyang was 10.8\% [3]; in 2008, the detection rate of behavior problems of school-age children in Yueyang was 9.19\% [4]. Thus, the author carries out an epidemiological survey on behavior problems of children from 8 to 14 years old in Linyi, in order to provide scientific basis for psychologists.

\section{Research Objects and Methods}

\subsection{Research objects.}

Linyi has nine counties and three districts. From June, 2013 to May 2016, researches selected one primary school from each county and each district. 1 class from each grade (third to sixth grade) was randomly selected as the object of investigation. A total of 2640 people were investigated. 2600 valid questionnaires were collected with the efficiency of $98.48 \%$, including 1520 for boys and 1080 for girls. The ages of children were 8 to 14 years old; the average age was $(10.09+1.47)$ years old.

\subsection{Research method.}

Research tool. The Rutter Children Behavior Questionnaire [5] was compiled by British psychiatrist Michael Rutter. This scale is suitable for school-age children and has been widely used in the study of children's behavior problems at home and abroad. Rutter Children Behavior Questionnaire includes parent questionnaire (31 items) and teacher questionnaire (26 items). Scores can be divided into 3 levels. "0" means the situation never happens; "1" means the situation happens sometimes or less than 1 time per week, or mild symptoms; "2" means the situation often happens, or at least 1 time per week. The critical values of parent and teacher questionnaires are 13 points and 9 
points. Children who get greater than or equal to the critical values are rated as children with behavior problems. Among those kids who have behavior problems, if the total score of their "A behavior" (disciplinary offence) is higher than the total score of "N behavior" (neurotic behavior), the children's problems will be marked as "A behavior"; otherwise their problems will be marked as "N behavior". The equal scores of $\mathrm{A}$ and $\mathrm{N}$ behaviors mean that the children have "M behavior" (mixed behavior) problem. Students' academic performances are evaluated at the front of teacher questionnaire. If the students' academic performances are better than 70\% (including 70) of their classmates, their performances will be marked as good; if the students' academic performances are better than $30 \%$ $70 \%$ (including 30\%) of their classmates, their performances will be marked as middle. Otherwise, their performances will be marked as bad. Family economic levels are evaluated at the front of parent questionnaire (divided into three levels: good, middle, bad).

Research method. After unified training, head teachers (who have been served as the head teacher for more than 3 months) were responsible for number and set Rutter parent and teacher questionnaires. The teacher questionnaires were filled out by head teachers according to the actual situation of each child. The meaning of investigation was explained to parents by head teachers through parents meeting or telephone (target parents who did not attend the parents meeting). After obtaining their consent, parent questionnaires were filled out by children's parents or guardians.

Statistical method. The original data were collected, collated and numbered. EpiData 3.1 was used to set up database for double entry and check; SPSS 13 was used for statistical analysis.

\section{Research Results}

\subsection{Behavior problems of boys and girls.}

According to parent questionnaire, there were 520 children with behavior problems; the detection rate was $20 \%$. $20.4 \%$ of boys and $19.4 \%$ of girls were detected as behavior problems. According to teacher questionnaire, there were 492 children with behavior problems; the detection rate was $18.9 \%$. $19.7 \%$ of boys and $17.8 \%$ of girls were detected as behavior problems. In the questionnaires of parent and teacher, the behavior problems of boys were more than those of girls (V2=31.44, 73.86, $\mathrm{P}<0.01$ ); the majority of boys' behavior problems were detected as type A, and the majority of girls' behavior problems were detected as type N. These data can be found in Table 1.

The coincidence rate between parent and teacher questionnaires was $77.3 \%$. The behavior problems of 173 children (6.7\%) were detected by both questionnaires; 1741 children (67\%) did not have behavior problems according to both questionnaires. Through paired X2 test, it was found that there was a statistically significant difference in consistency (V2=98.17, $\mathrm{P}<0.01$ ).

Table 1 Rutter questionnaire on detection rates of various types of behavior problems: comparison between boys and girls / \%

\begin{tabular}{|c|c|c|c|c|c|c|c|}
\hline \multirow{2}{*}{ gender } & \multirow{2}{*}{ number } & \multicolumn{3}{|c|}{ Parent questionnaire } & \multicolumn{3}{c|}{ Teacher questionnaire } \\
\cline { 3 - 8 } & & Type A & Type N & Type M & Type A & Type N & Type M \\
\hline male & 1520 & 8.5 & 8.3 & 4.1 & 8.7 & 4.2 & 1.2 \\
\hline female & 1080 & 4.3 & 7.5 & 4.0 & 3.2 & 3.6 & 0.8 \\
\hline total & 2600 & 6.4 & 7.9 & 4.1 & 6.0 & 3.9 & 1.0 \\
\hline
\end{tabular}

Table 2 Rutter questionnaire on detection rates of various types of behavior problems: comparison between children come from different regions $/ \%$

\begin{tabular}{|c|c|c|c|c|c|c|c|}
\hline \multirow{2}{*}{ region } & \multirow{2}{*}{ number } & \multicolumn{3}{|c|}{ Parent questionnaire } & \multicolumn{3}{c|}{ Teacher questionnaire } \\
\cline { 3 - 8 } & Type A & Type N & Type M & Type A & Type N & Type M \\
\hline urban & 1101 & 6.3 & 7.5 & 4.2 & 7.1 & 6.2 & 4.3 \\
\hline rural & 997 & 6.8 & 8.4 & 5.1 & 8.2 & 4.5 & 5.6 \\
\hline $\begin{array}{c}\text { Migrant } \\
\text { worker }\end{array}$ & 502 & 8.4 & 9.1 & 5.6 & 7.5 & 5.4 & 4.3 \\
\hline total & 2600 & 7.2 & 8.3 & 5.0 & 7.6 & 5.4 & 4.7 \\
\hline
\end{tabular}




\subsection{Behavior problems of children from different regions.}

Significant statistically difference could be found in the detection rate of parent questionnaire (V2=16.74, $\mathrm{P}<0.01)$. The majority of behavior problems of children from urban primary school (18\%), rural primary school (20.3\%) and primary school for peasant worker (23.1\%) were Type $\mathrm{N}$ problems. No significant statistically difference could be found in the detection rate of teacher questionnaire of behavior problems (V2=9.74, $\mathrm{P}>0.05$ ). The majority of behavior problems of children from urban primary school (17.6\%), rural primary school (18.3\%) and primary school for peasant worker (17.2\%) were Type A problems. These data can be found in Table 2.

\subsection{Behavior problems of children with different academic performances.}

There were significant differences in both parent and teacher questionnaires (V2=32.35, $\mathrm{P}<0.01$ ) (V2=57.61, $\mathrm{P}<0.01$ ). In the parent questionnaire, the detection rate of behavior problems was higher in children with bad academic performances. Most students with lower scores had more Type A behaviors; children with middle or good academic performances had more Type $\mathrm{N}$ behaviors. In teacher questionnaire, the detection rate of behavior problems in children with bad academic performances was also higher. Among them, students with lower or middle scores had more Type A behaviors, while children with high scores had more Type $\mathrm{N}$ behaviors. These data can be seen in Table 3.

Table 3 Rutter questionnaire on detection rates of various types of behavior problems: comparison between children with different academic performances / \%

\begin{tabular}{|c|c|c|c|c|c|c|c|}
\hline \multirow{2}{*}{$\begin{array}{c}\text { Academic } \\
\text { performance }\end{array}$} & \multirow{2}{*}{ number } & \multicolumn{3}{|c|}{ Parent questionnaire } & \multicolumn{3}{c|}{ Teacher questionnaire } \\
\cline { 3 - 8 } & & Type A & Type N & Type M & Type A & Type N & Type M \\
\hline bad & 1050 & 8.7 & 7.5 & 5.8 & 10.2 & 7.5 & 7.1 \\
\hline middle & 1142 & 6.5 & 7.3 & 4.8 & 7.6 & 6.5 & 4.8 \\
\hline good & 408 & 6.4 & 7.7 & 5.2 & 6.5 & 7.1 & 5.4 \\
\hline total & 2600 & 7.2 & 7.5 & 5.27 & 8.1 & 7.03 & 5.77 \\
\hline
\end{tabular}

\subsection{Behavior problems of children from families with different economic conditions.}

There were significant differences in both parent and teacher questionnaires (V2=14.51, $\mathrm{P}<0.05$ ) (V2=15.46, $\mathrm{P}<0.05$ ). In the parent questionnaire, the detection rate of behavior problems in children from poor families was high. Most students from low or middle class families had more Type $\mathrm{N}$ behaviors, while children from wealthy families had more Type A behaviors. In teacher questionnaire, the detection rate of behavior problems in children from poor families was also higher. All children from these three kinds of families had more Type A behaviors. These data can be seen in Table 4 .

Table 4 Rutter questionnaire on detection rates of various types of behavior problems: comparison of children from families with different economic conditions $/ \%$

\begin{tabular}{|c|c|c|c|c|c|c|c|}
\hline \multirow{2}{*}{$\begin{array}{c}\text { Economic } \\
\text { condition }\end{array}$} & \multirow{2}{*}{ number } & \multicolumn{3}{|c|}{ Parent questionnaire } & \multicolumn{3}{c|}{ Teacher questionnaire } \\
\cline { 3 - 8 } & & Type A & Type N & Type M & Type A & Type N & Type M \\
\hline bad & 738 & 7.8 & 10.5 & 8.4 & 10.2 & 8.9 & 7.5 \\
\hline middle & 1652 & 7.1 & 8.8 & 6.5 & 8.8 & 7.6 & 7.4 \\
\hline good & 210 & 7.0 & 6.8 & 5.1 & 7.6 & 7.1 & 5.6 \\
\hline total & 2600 & 7.3 & 8.7 & 6.67 & 8.87 & 7.87 & 6.83 \\
\hline
\end{tabular}


Table 5 Rutter questionnaire on detection rates of various types of behavior problems: comparison of children and parents' educational levels /\%

\begin{tabular}{|c|c|c|c|c|c|c|c|c|}
\hline \multirow{2}{*}{ parents } & \multirow{2}{*}{$\begin{array}{c}\text { Education } \\
\text { degree }\end{array}$} & \multirow{2}{*}{ number } & \multicolumn{3}{|c|}{ Parent questionnaire } & \multicolumn{3}{c|}{ Teacher questionnaire } \\
\cline { 4 - 9 } father & Primary school & 770 & 7.5 & 7.8 & 6.8 & 6.2 & 4.5 & 5.5 \\
\cline { 2 - 9 } & Middle school & 1600 & 7.4 & 7.8 & 6.1 & 6.5 & 6.4 & 6.1 \\
\cline { 2 - 9 } & $\begin{array}{c}\text { Higher } \\
\text { education }\end{array}$ & 230 & 6.8 & 7.1 & 5.1 & 5.7 & 5.1 & 4.2 \\
\cline { 2 - 9 } & total & 2600 & 7.2 & 7.6 & 6.0 & 6.1 & 5.3 & 5.3 \\
\hline \multirow{5}{*}{ mother } & Primary school & 820 & 8.4 & 9.1 & 7.2 & 5.6 & 5.4 & 4.2 \\
\cline { 2 - 9 } & Middle school & 1531 & 7.5 & 8.1 & 5.8 & 5.1 & 4.2 & 4.3 \\
\cline { 2 - 9 } & $\begin{array}{c}\text { Higher } \\
\text { education }\end{array}$ & 249 & 5.6 & 6.1 & 4.2 & 4.1 & 3.2 & 3.1 \\
\cline { 2 - 9 } & total & 2600 & 7.2 & 7.8 & 5.7 & 4.9 & 4.3 & 3.9 \\
\hline
\end{tabular}

\subsection{Children's behavior problems and parents' educational levels.}

In parent questionnaire, the differences of educational levels of both father and mother made significant differences (V2=16.16, 16.28, both $\mathrm{P}$ values $<0.01$ ). The detection rate of behavior problems in children with low educational level parents was high. Most students from these three groups had more Type $\mathrm{N}$ behaviors. In teacher questionnaire, no significant difference was found (V2=9.98, 12.13, both $\mathrm{P}$ values $>0.05$ ). All children from these three kinds of families had more Type A behaviors. These data can be found in Table 5 .

\section{Discussions}

\subsection{Behavior problems of boys are more than those of girls.}

According to both parent and teacher questionnaires, boys have more behavior problems than girls. It also verifies related reports [6]. Most of boys' problem behaviors are Type A, while most of girls' problem behaviors are Type $\mathrm{N}$. This phenomenon may be rooted in the characteristics of genders, and the different social expectations on male and female. Relatively speaking, the society approves girls' emotional reactions (Type $\mathrm{N}$ behaviors) and boy's aggressive behavior (Type A behaviors). In addition, this paper is consistent with the reports of Zheng Yan and his colleges [7]. The reason may be related to persons who fill in the scales. Teachers are more concerned about students' discipline violations, while parents and dependants are more concerned about children's physical health.

\subsection{Behavior problems of children from migrant worker families are more serious.}

The parent questionnaire shows that the behavior problems of migrant workers' children are more serious than those of children who live in countryside or urban areas. The teacher questionnaire shows no difference on behavior problems between children from different regions. One possible reason is that migrant workers' children do not have city residence; they cannot enjoy equal rights on education and health care like urban kids. Although they live in the city, the urban and rural differences cannot be eliminated. In addition, most children of migrant workers come from backward areas, where all kinds of conditions are worse than conditions of peri-urban countryside. The environment and growth gaps lead to more prominent behavior problems of migrant workers' children. But the opportunity of studying in school is very precious for children of migrant workers. So they are more disciplined at school. They attend to classes and complete their homework on time. So they have relatively less behavior problems at school.

\subsection{Children with poor academic performances are more likely to have behavior problems.}

Related research [8] believes that with the progress and improvement of learning achievement, children's behavior problems will be reduced. Children's behavior problems and learning achievement influence each other. Behavior problems can inhibit students' potentials, resulting in 
adverse effects on learning; conversely, learning achievement also affects students' behavior. Listening to their parents at home, listening carefully at class, and completing homework on time are premise of good academic results. Thus, students with good academic results also have good performances at school. They can get teacher's praise for hard working and discipline, and they are willing to keep these good behaviors at home in order to get parents' praise. Hence, school education brings good effects on the performances of children at home. As for students with poor academic performances, they are under the pressure of school, parents and classmates; the pressure may cause or aggravate their bad behaviors.

\subsection{Children come from poor families and children who have parents with low cultural degrees have more behavior problems.}

Children who have better family economic conditions generally have less behavior problems. [9] Economically well-off families can provide children with good teaching conditions and enable them to receive good education. The cultural degrees of parents determine their outlook on life, as well as their values and ethics. Children have most interactions with their parents; the manners and education methods of parents affect children directly or indirectly. In addition, highly educated parents are engaged in more decent and well-paid careers, which will further affect the growth of children through good economic conditions. Parents should continue to learn scientific nurturing knowledge, adopt scientific and consistent educational methods, and encourage their children to make their children develop steadily.

\section{Suggestion}

Society, school and family should pay more attention to the lives and mental health of children of migrant workers.

The academic achievements should not become the only criterion to judge children, in order to avoid children's psychological problems brought by poor academic performance.

The educational level of parents affects their educational methods, and will affect children's growth. Therefore, parents should constantly improve their educational levels and learn some childcare knowledge.

\section{References}

[1] National Collaborative Investigation Group of 22 Cities, Factors influencing children's behavior problems: collaborative survey report of 22 cities, 24013 children and juveniles, J. Chinese Mental Health Journal. 7 (1993).

[2] Y. Wang, M.Y. Gan, Analysis on epidemiological characteristics of behavior problems in school age children of Beijing, J. Maternal and Child Health Care of China. 24 (2009).

[3] C.Y. Bai, D. Zhang, H. Zhou, et al., Analysis of school children's behavior problems and family environment in Shenyang, J. Chinese Journal of School Health. 27 (2006).

[4] B.Y. Fu, K.Q. Liu, D.L. Han, Study on behavior problems of school-age children in Yueyang, J. Practical Preventive Medicine. 15 (2008).

[5] X.D. Wang, X.L. Wang, H. Ma (Eds.), Mental Health Assessment Handbook, revised ed., Chinese Mental Health Journal Publisher, Beijing, 1999.

[6] X.H. Zhang, Y.Q. Wu, W. Lu, Study on behavior problems of school-age children. J. Modern Preventive Medicine. 33 (2006).

[7]Z. Yan, X.Q. Ke, X.J. Ye, et al., The relationship between school-age children's behavior problems and their genders, ages and household registrations, J. Journal of Sichuan University (Medical Science Edition). 37 (2006).

[8] C.F. Li, F.B. Tao, H.B. Zhang, Research on the relationship between children's behavior problems and their academic achievements, J. Chinese Journal of Behavioral Medical Science. 14 (2005).

[9] S.W. Yang, X.Y. Lin, Y.S. Yu, et al., Behavior problems and influencing factors of 3 6 years old children in ethnic minority areas, J. Modern Preventive Medicine. 34 (2007). 